\title{
Ideas of Plato in the Context of Contemporary Science and Mathematics
}

\author{
By Mark Burgin*
}

For millennia, the enigma of the world of Ideas or Forms, which Plato suggested and advocated, has been challenging the most prominent thinkers of the humankind. This paper presents a solution to this problem, namely, that an Idea in the Plato's sense can be interpreted as a scientific object called a structure. To validate this statement, this paper provides rigorous definition of a structure and demonstrates that structures have the basic properties of Plato's Ideas. In addition, we describe the world of structures and prove its existence. This allows us to resolve the controversy between Plato and Aristotle concerning Ideas or Forms and to build a scientific interpretation of the metaphor of the Divided Line, which Plato uses in his theory of Ideas.

\section{Introduction}

Plato (427-347 B.C.E.) is one of the greatest philosophers of all times and all nations. His ideas had a formative impact on a diversity of philosophers and scientists. He contributed to many fields of philosophy. Here we are interested mostly in his ontological conceptions.

Classical Greece gave many great ideas to the world. Two of them described the structure of our world. One was introduced by Leucippus of Miletus (ca. 480 - ca. 420 B.C.E.) and Democritus from Abdera (460-370 B.C.E.), who suggested that the universe consisted of a void and a large number of invisible and indivisible particles, which were called atoms. In this picture, all things were built of atoms.

Plato also pioneered the second great idea asserting that the world as a whole consisted of two realms: the physical world, which people could comprehend with their five senses, and the world of Ideas or Forms, which people could comprehend only with their intellect. This teaching on Ideas or Forms is at the heart of Plato's philosophy shaping his views on knowledge, ethics, esthetics, psychology and political teachings.

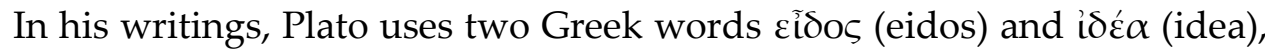
which were later translated as Idea in the Latin and German tradition and as Form in the English tradition. However, here we use the term Idea as a general concept and the term Form as it particular case.

Note that usually Plato's teaching on Ideas or Forms is called the theory of Forms or the theory of Ideas. However, it is debatable whether there are theories in philosophy. According to the contemporary methodology of science, actual

\footnotetext{
${ }^{*}$ Visiting Scholar, University of California, USA.
} 
theories exist only in science and mathematics (cf., for example Mark Burgin, \& Vladimir Kuznetsov ${ }^{1}$ ) although a broader understanding of the term theory allows using the name theory for different philosophical teaching. Thus, we will call Plato's teaching about Ideas by the name the theory of Ideas or Forms as he did not make a distinction between Ideas and Forms.

In spite of the great interest in the philosophy of Plato in general and in the world of Ideas in particular, for a long time, neither philosophers nor other researchers were able to explain clearly and consistently what Plato Ideas are. The enigma of the world of Ideas constituted one of the longest standing philosophical and scientific problems in the history of humankind. Only at the end of the $20^{\text {th }}$ century, that is more than two millennia after Plato, the author discovered that the concept structure provides the scientific representation of Platonic Ideas, while the existence of the world of structures, which can be naturally equated to the world of Ideas, was postulated and proved. ${ }^{2}$

The goal of this paper is to demonstrate in a transparent and persuasive way that structures studied in contemporary mathematics and science provide a scientific explanation and representation for Plato teaching about Ideas in the same way as subatomic particles studied in contemporary physics provide a scientific reflection of the teaching of Leucippus and Democritus about atoms. To achieve this goal, the paper is organized as follows. Next section reminds the reader of Plato's teaching about the world of Ideas or Forms. Note that describing Plato's teaching, we do not distinguish Ideas and Forms because Plato did not do this. Subsequently, we explain why and how this world is interpreted as the world of structures, and provide formal and informal definitions of structures demonstrating that structures have the basic properties of Plato's Ideas. Then, we exhibit how the conception of structures as Ideas or Forms allows solving the controversy between Aristotle and Plato, as well as providing a scientific interpretation of the metaphor of Plato's Divided Line. Finally, in Conclusion, we discuss how technological and scientific achievements change our understanding of the sensibility of the physical world and intelligibility of the world of Ideas.

1. Mark Burgin, \& Vladimir Kuznetsov, Introduction to Modern Exact Methodology of Science (Moscow: International Science Foundation, 1994) (In Russian).

2. Mark Burgin, Structural Reality (New York: Nova Science Publishers, 2012), Theory of Information: Fundamentality, Diversity and Unification, World Scientific (New York, London, Singapore, 2010), \& — Fundamental Structures of Knowledge and Information (Kiev: Ukrainian Academy of Information Sciences, 1997) (In Russian). 


\section{Two Worlds Postulated by Plato}

Now let us look in more detail at Plato's theory of Ideas or Forms where the world as the whole is structured into two distinct worlds - the physical world and the world of Ideas. ${ }^{3}$

To explain the relations between the physical world and the world of Ideas or Forms, Plato uses the Allegory of the Cave described in the Republic. In this allegory, Plato compares people to prisoners confined to a cave for the whole life and chained so that they are turned away from the entrance of the cave being unable to turn either themselves or their heads. Near the entrance of the cave, a big fire burns. Between the fire and the prisoners, there is a parapet. Other people are walking there holding up the real objects as puppeteers hold up their puppets. These real objects, which are behind the prisoners but in front of the fire, cast shadows on the wall of the cave open to the prisoners. The prisoners, unable to turn their heads, cannot see these real things. What the prisoners can see are shadows cast by objects and always hear echoes of the sounds of the people holding real things the prisoners do not see directly. As a result, the prisoners confuse appearance with reality. They believe what they see on the wall (the shadows) is real but they know nothing of the real causes of the shadows. In the same way, compared with the reality of the world of Ideas, physical objects and events are only shadows. Being the ultimate reference points for all objects people see in the physical world, Ideas are more real than these objects. Therefore, the general terms of people's languages are not names of the physical objects but the names of Ideas or Forms, which people can only grasp with the mind.

Only released, the prisoners can turn their heads, see the real objects and realize their error. Such liberation can come only through intelligence. Plato conceives that correct knowledge is no more than the knowledge of Ideas because what came through our senses is not knowledge of the thing itself but only knowledge of the imperfect changing copy of some Idea. Thus, the only possible manner to acquire correct knowledge of Ideas is through reasoning as senses can provide only opinions and reasoning is the way to liberation from the cave. Compare this with the Meno, where Plato treats knowledge acquisition as recollection of Ideas latent in the soul.

This is a beautiful allegory but the crucial questions are what these Ideas or Forms are, where they are and how people can know about them. Plato says they are perfect templates, which exist somewhere in another realm, which is cognizable only by the intellect. However, neither Plato nor other thinkers have persuasively told us where this world is situated, and nobody has consistently described these Ideas.

3. Plato, The Collected Dialogues of Plato (Princeton: Princeton University Press, 1961). 


\section{The World of Ideas as the World of Structures}

Thus, having no empirical evidence for and clear understanding of the World of Ideas, many philosophers and scientists, starting with Aristotle, argue that the World of Ideas brings about many problems. Where is this world of Ideas and how do people contact and comprehend it? What is an Idea in this sense? How is it possible for the mind to interact with the Platonic realm so that the brain receives information about Ideas? Plato and his followers have not provided convincing answers to these questions. For instance, some researchers write that Forms are abstract properties or qualities. However, the notion of an abstract property or quality is not clearer than the notion of a Form or Idea. In a similar way, the assertion that Forms/Ideas are archetypes of physical objects simply reveals one of the characteristics of Forms/Ideas given by Plato.

That is why, in spite of the attractive character of the theory of Ideas, the majority of scientists, philosophers and other intellectuals strongly believe that the world of Ideas does not exist, because nobody has been able to find any positive evidence in support of it. The crucial argument of physicists is that the main methods of verification in modern science are observations and experiments, and nobody has been able to find this world by means of observations and experiments. Nevertheless, in the $20^{\text {th }}$ century, there were outstanding modern thinkers, such as the philosopher Karl Raimund Popper, mathematician Kurt Gödel and physicist Roger Penrose, who believed that the world of Ideas existed. They and other intellectuals before them gave various interpretations of this world but suggested no means for experimental validation.

For instance, starting with ideas of Plato, Plotinus (c.a. 205 - 270 C.E.), who is generally regarded as the founder of Neoplatonism and one of the most influential philosophers in antiquity after Plato and Aristotle, further developed the theory of Ideas/Forms by stratifying the incorporeal realm of Ideas with three principles. ${ }^{4}$ The three basic tenets of Plotinus' metaphysics are "the One" (or "the Good"), Intellect, and Soul. The One is the prime principle, which is "self-caused" and the cause of existence for everything else in the universe. The Intellect is the system of Ideas/Forms and is the first derivation from the One. The role of Intellect is to establish distinctness of the abundance of Forms, which are virtually amalgamated in the One. The Soul is the derivation from Intellect being the principle of desire for objects that are external to the agent of desire.

However, we can see that the new description of the incorporeal realm of Ideas developed the theory but added vagueness and commotion generating new questions about the theory of Ideas/Forms.

4. Lloyd Gerson, Plotinus (The Stanford Encyclopedia of Philosophy, 2014). 
Popper, one of the major philosophers of the $20^{\text {th }}$ century, suggested another approach by trying to explicate the incomprehensible world of Ideas/Forms introducing the world 3 of abstract or intellectual products of the human mind. Examples of such products are languages, tales, stories, contents of books, movies and documents, music, scientific conjectures and theories, mathematical constructions and engineering schemas, etc. ${ }^{5}$ According to Popper, this world 3 together with the world 1 of physical bodies, including microparticles, physical processes, physical energy and physical fields, and the world 2 of thoughts, feelings, decisions, perceptions, observations, etc. constitutes the world as a whole.

To define the world 3, Popper writes:

"If we call the world of "things" or of physical objects - the first world, and the world of subjective experiences (such as thought processes) the second world, we may call the world of statements in themselves the third world ....

It would be easy ... to regard the whole of world 3 as timeless, as Plato suggested of his world of Forms or Ideas ... I propose a different view one which, I have found, is surprisingly fruitful. I regard world 3 as being essentially the product of the human mind ... . More precisely, I regard the world 3 of problems, theories, and critical arguments as one of the results of the evolution of human language, and as acting back on this evolution."6

Thus, we can see that Popper's interpretation is inconsistent with Plato's world of Forms/Ideas because Platonic Ideas are eternal and perfect, while the products of the human mind are temporary and imperfect. In addition, Plato's Ideas are not mental entities, nor even mind-dependent. They are independently existing objects, the being and nature of which are comprehensible only by the mind, even though they do not depend on this comprehension in order to exist.

However, it was much easier to understand Popper's world 3 than Plato's world of Ideas. In spite of this more realistic interpretation the abstract nature of world 3 caused criticism and many questions about it real existence. As a result, Popper decided to extend this world adding other products of the human mind, such as books and cars, paintings and sculptures, ships and

5. Karl Popper, Replies to my critics, The Philosophy of Karl Popper (Open Court, La Salle, IL, 1974) \& __ Objective knowledge: An evolutionary approach (New York: Oxford University Press, 1979).

6. ___ Replies to my critics. 
planes, as well as other feats of engineering. ${ }^{7}$ Therefore, world 3 acquired parts that also belonged to world 1 . This feature is completely inconsistent with Plato's Ideas.

There were also attempts to interpret the world of Ideas as the world of signs in the sense of Charles Saunders Peirce. ${ }^{8}$

The prominent physicist Roger Penrose suggested his interpretation of the world of Forms or Ideas treating it as the world of mathematical truths. This did not make things clearer because the notion of truth is vague and imprecise.

Nevertheless, the progress of science and mathematics brought forth the discovery of the world of structures, ${ }^{9}$ allowing the researchers to solve the mystery of Platonic Forms and Ideas and to consistently represent Popper's world 3. We can see that on the level of ideas, it is possible to associate this world with the Platonic world of Ideas or Forms in the same way as we may relate the atoms of modern physics to the atoms of Leucippus and Democritus. At the same time, in contrast to Plato, science has been able to prove existence of the world of structures, demonstrating by means of observations and experiments, that this world constitutes the structural level of the world as the whole. Each system, phenomenon or process whether in nature or in technology or in society has some structure. These structures exist like material things, such as mountains, chairs, trees or buildings do, and form the structural level of the world. When it is necessary to learn or to create some system or generate a process, it is done, as a rule, by understanding or development of the corresponding structure as structures determine the essence of things.

In the next section, we examine existing definitions of the concept structure; elaborate the most advanced definition, which encompasses not only mathematical structures but any kind of structures; and show that the world of structures is consistent with Plato's theory of Ideas or Forms.

7. ___ Objective knowledge: An evolutionary approach.

8. Peter Skagestad, Thinking with machines: Intelligence augmentation, evolutionary epistemology, and semiotics, Journal of Social and Evolutionary Systems 16 (1993); \& Rafael Capuro, \& Birger Hjorland, The Concept of Information, Annual Review of Information Science and Technology 37, no. 8 (2003).

9. Mark Burgin, What is the Surrounding World Built of (The Ontological Aspect), Philosophical and Sociological Thought no. 8 (1991) (In Russian) \& _ Is it Possible that Mathematics gives new Knowledge about Reality? Philosophical and Sociological Thought no. 1 (1994) (In Russian and Ukrainian) \& __ Fundamental Structures of Knowledge and Information. 


\section{The Concept of a Structure}

Without exact definition of the concept structure, the world of structures would remain as vague and incomprehensible as the world of Ideas or Forms. Therefore, we analyze definitions that different researchers have suggested. Based on this analysis, we develop a comprehensive definition of a structure.

Looking at the ordinary usage of the word structure, we see that on the intuitive level, structure means a complex of objects and relations comparable with one another in principle. There are also more exact definitions. For instance, Grossmann ${ }^{10}$ defines a structure in the following way.

Definition 1: A structure is (a representation of) a complex entity that consists of parts in relations to each other.

This definition implies that two structures are identical if and only if: (a) their nonrelational parts are the same; (b) their relations parts are the same; and (c) corresponding parts stand in corresponding relations. A similar definition of a mathematical structure is used in logic and mathematics. ${ }^{11}$

Definition 2: A mathematical structure is an abstract (symbolic) system,

$$
A=\left\langle M ; R_{1}, R_{2}, \ldots, R_{n}>\right.
$$

where $M$ is a set and $R_{1}, R_{2}, \ldots, R_{n}$ are relations in this set.

Note that in mathematics, a relation in a set $M$ is a subset of the Cartesian product $M \times M \times \ldots \times M$.

Some mathematicians ${ }^{12}$ use the name model or relational system for the concept defined in Definition 2. Physicists and other scientists understand mathematical structures in a similar way. For instance, Tegmark ${ }^{13}$ gives Definition 3.

Definition 3: A mathematical structure is a system that consists of:

1. The set of entities that belong to the union $S=S_{1} \cup S_{2} \cup \ldots \cup S_{n}$ of sets $S_{1}, S_{2}, \ldots, S_{n}$.

2. Functions (functional relations) on these sets and their Cartesian products,

10. Reinhardt Grossmann, The Fourth Way: A Theory of Knowledge (Bloomington, Indianapolis: Indiana University Press, 1990).

11. Abraham Robinson, Introduction to Model Theory and Metamathematics of Algebra (Amsterdam, New York: North-Holland, 1963); \& Isaac Yaglom, Mathematical Structures and Mathematical Modeling (Moscow: Sov. Radio, 1980) (In Russian).

12. Anatolij Malcev, Algebraic systems (Springer, 1973).

13. Max Tegmark, The Mathematical Universe, Foundations of Physics 38, no. 2 (2008). 


$$
R_{k}: S_{i 1} \times S_{i 2} \times \ldots \times S_{i t} \rightarrow S_{n}
$$

In their informal definition of a mathematical structure, mathematicians from the French group with the pseudonym Nicolas Bourbaki ${ }^{14}$ add one more condition - axioms.

Definition 4: A mathematical structure is a set with relations in this set and axioms that these relations satisfy.

It is necessary to remark that Bourbaki ${ }^{15}$ also elaborated a formal definition of a general mathematical structure as an exact but very abstract concept. However, their formal definition is essentially much more complicated and much longer than their informal definition, covering several pages in the book. ${ }^{16}$ Besides, the formal definition is too sophisticated and complex even for the majority of mathematicians, who prefer using the informal notion of a mathematical structure or the definition where a structure is formalized as a set with relations in it. As Corry ${ }^{17}$ writes, Bourbaki's concept of structure was, from the mathematical point of view, a superfluous undertaking. Even Bourbaki themselves did not use this concept in their later books of the Eléments after they had introduced it in Theorie des Ensembles. ${ }^{18}$

Besides, we can see that this definition is not only too complicated but is also counter-intuitive because Bourbaki describe a structure as a term, i.e., a logical formula. However, a structure may be described or characterized by a formula but a formula can be only a specialized (logical) structure.

In addition, specific terms are called sets in the process of defining a structure. ${ }^{19}$ However, terms are names of sets in formalized set theories but they are not sets themselves. In real life, there is a difference between objects and their names. A similar difference exists between mathematical objects and their formal or informal names. A new definition is elaborated in the general theory of structures.

Definition 5: A structure $Q$ consists of elements/parts, which belong to this structure $Q$, and relations of three types:

14. Nicolas Bourbaki, L'architecture des mathématiques, Legrands courants de la pensée mathématiques (The architecture of mathematics, Great currents of mathematical thinking) Les Cahiers du Sud (1948).

15. __ Structures (Paris: Hermann, 1957); \& — Theorie des Ensembles (Theory of Sets) (Paris: Hermann, 1960).

16. __ Theorie des Ensembles.

17. Leo Corry, Modern Algebra and the Rise Mathematical Structures (Basel, Boston, Berlin: Birkhäuser, 1996).

18. Bourbaki, Theorie des Ensembles.

19. Ibid. 
1. Relation between elements/parts of $Q$.

2. Relation between elements/parts of $Q$ and relations of $Q$.

3. Relation between relations of $Q$.

Note that conventional definitions of structure take into account only relations of the first type. ${ }^{20}$ Two other types were discovered only in the general theory of structures. ${ }^{21}$

The most fundamental structures are called named sets or fundamental triads, which are described in next section. There two primary kinds of named sets (fundamental triads) - ordinary named sets (fundamental triads) and bidirectional named sets (fundamental triads) although a bidirectional named set is a composition of two ordinary named sets. It is proved in Burgin, ${ }^{22}$ that all other structures are either named sets (fundamental triads) or are built of named sets (fundamental triads).

The described in Definition 5 typology of relations allows us to build a hierarchy of relations in a structure.

A. A relation of the first level in a structure $Q$ is a relation between the elements from the structure $Q$.

B. There are two kinds of relations of the second level in a structure $Q$ :

1. relations between the elements from $Q$ and relations of the first level in $Q$;

2. relations between relations of the first level in $Q$.

C. There are two kinds of internal relations of the $n$-th level in a system $M$ :

1. relations between the elements of $Q$, relations of the $(n-1)$-th level in $M$ and perhaps relations of the $(n-2)$-th and lower levels in $M$;

2. relations between relations of the $(n-1)$-th and relations of the $(n-$ 1)-th and lower levels in $M$.

The level of relations stratifies the system of all relations and defines the structural hierarchy (Figure 1). It is described in the following way. At the first

20. Abraham Robinson, Introduction to Model Theory; Isaac Yaglom, Mathematical Structures and Mathematical Modeling; Reinhardt Grossmann, The Fourth Way: A Theory of Knowledge; Max Tegmark, The Mathematical Universe.

${ }^{21}$ Mark Burgin, Structures in mathematics and beyond, Proceedings of the $8^{\text {th }}$ Annual International Conference on Statistics, Mathematics and Related Fields (Honolulu, Hawaii, 2009); __ Theory of Information: Fundamentality, Diversity and Unification; \& _ Structural Reality.

22. ___ Theory of Named Sets (New York: Nova Science Publishers, 2011). 
level, we have the set $\mathfrak{I}_{0}$ of all objects from this structure. On the second level of the structural hierarchy, we have the set $\mathfrak{R}_{1}$ of all relations between objects from this structure. At the second level, we have two sets:

- $\mathfrak{R}_{01}$ is the set of all relations between objects from this structure, which form the set $\mathfrak{I}_{0}$, and relations from $\mathfrak{R}_{1}$,

- $\mathfrak{R}_{11}$ is the set of all relations between relations from $\mathfrak{R}_{1}$.

At the third level, we have five sets:

- $\mathfrak{R}_{(0)(01)}$ is the set of all relations between objects from this structure, which form the set $\mathfrak{I}_{0}$, and relations from $\mathfrak{R}_{01}$,

- $\mathfrak{R}_{(1)(01)}$ is the set of all relations between relations from $\mathfrak{R}_{1}$ and relations from $\Re_{01}$,

- $\mathfrak{R}_{(0)(11)}$ is the set of all relations between objects from this structure, which form the set $\mathfrak{I}_{0}$, and relations from $\mathfrak{R}_{11}$,

- $\mathfrak{R}_{(1)(11)}$ is the set of all relations between relations from $\mathfrak{R}_{1}$ and relations from $\mathfrak{R}_{11}$,

- $\mathfrak{R}_{(01)(11)}$ is the set of all relations between relations from $\mathfrak{R}_{01}$ and relations from $\Re_{11}$.

Then we can build the fourth level, the fifth level and so on. In general, relational hierarchy can grow as far as we want and even be infinite for some structures.

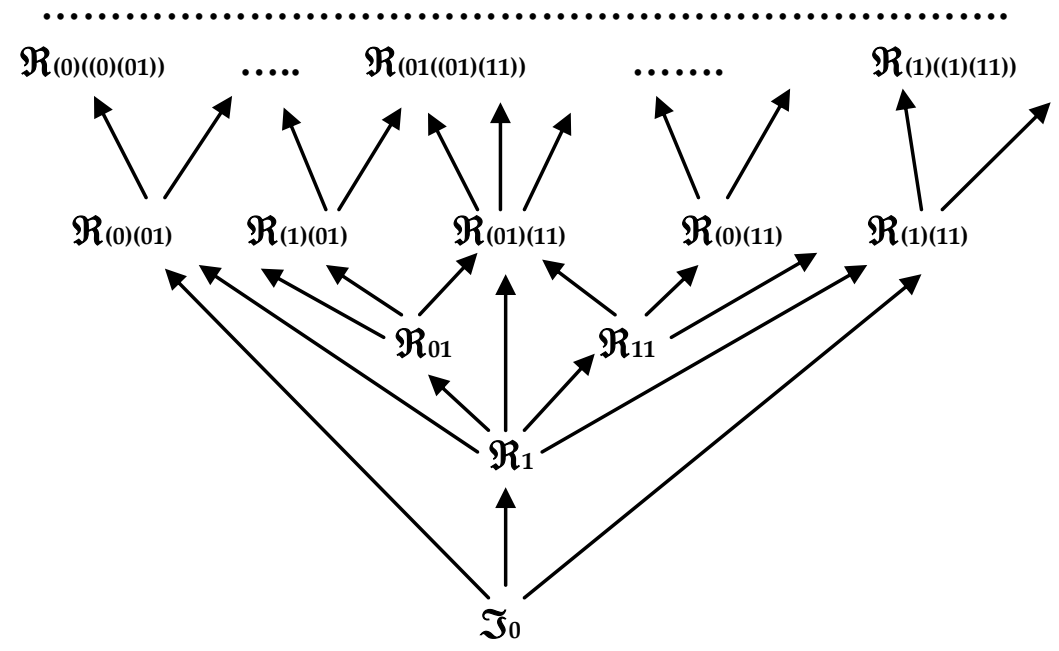

Figure 1. Four Levels of the Relational Hierarchy 
The relational hierarchy induces the structural hierarchy in the following way:

- A structure $Q$ has order 1 if it has relations only of the first level.

- A structure $Q$ has order $n$ if it has relations only of the level $n$ and lower levels.

For instance, a fundamental triad has order 1. At the same time, the order of such a mathematical structure as a functional is 3 or more. Structures are intrinsically related to systems.

Mathematical definitions of structure show that there are two classes of structures: set-theoretical structures, which consist of basic elements and relations, and mereological structures, which are based on such an area as mereology $y^{23}$ and consist of parts, which may be essentially connected, having common subparts. For instance, it is possible to consider the structure of the human organism, which consists of parts such as the body, head, neck, arms and legs. We also have relations between these parts: the neck, legs and arms are connected to the body, while the head is connected to the neck. Here the emphasis is on set-theoretical structures because mathematical structures are, as a rule, set-theoretical.

In the general theory of structures, introduction to which Burgin presents in the book "Structural Reality"24 there are two sorts of structures: abstract structures and embodied structures. An embodied structure is a structure of some system, while an abstract structure is a structure by itself.

To make the concept of an embodied structure exact and complete, we need a definition of a system, which makes the difference between structures and systems apparent.

Definition 6: A system is a collection of objects connected with one another forming an intrinsic unity. Note that it is possible to treat a structure as an abstract system.

According to the general theory of structures, ${ }^{25}$ there are five types of embodied structures:

1. An internal structure $T Q$ of a system $R$ contains only inner structural parts, components and elements, i.e., parts, components and elements

23. Stanisław Leśniewski, Podstawy ogólnej teoryi mnogosci I, Prace Polskiego Kola Naukowego w Moskwie, Sekcya matematyczno-przyrodnicza, 1916 [trans. Foundations of the General Theory of Manifolds I, Stanisław Leśniewski, Collected Works (Dordrecht: Kluwer 1 (1992))]; \& Peter Simons, Parts: A Study in Ontology (Oxford: Oxford University Press, 1987).

24. Mark Burgin, Structural Reality.

25. Ibid. 
of $R$, relations between these parts, components and elements, relations between these parts, components, elements and relations from $T Q$ and relations between relations from $T Q$.

2. An inner structure IQ of a system $R$ is a substructure of an internal structure $T Q$ of $R$, where $I Q$ is obtained by exclusion of (1) the whole system $R$ as a part, component or element of itself and (2) all relations that include $R$.

3. An external structure $E Q$ of a system $R$ is an extension of the internal structure, in which other systems, their parts, components and elements are included, as well as relations between all these included parts, components and elements, relations between these parts, components, elements and relations from $E Q$ and relations between relations from $E Q$.

4. An intermediate structure $M Q$ of a system $R$ is a substructure of an external structure $E Q$ of $R$, where $M Q$ is obtained by exclusion of (1) the whole system $R$ and other systems from $E Q$, as well as (2) all relations that include these systems.

5. An outer structure $O Q$ of a system $R$ is an inner structure of a system $U$ in which $R$ is only one of the inner elements of the inner structure $I Q$ of the system $U$.

To show that the world of structures is consistent with the Plato's theory of Ideas or Forms, let us compare properties of Ideas/Forms, which Plato ascribes to them, and properties of structures as abstract objects.

In the dialogues Phaedo, Phaedrus and Timaeus, Plato gives an extended description of the characteristics, properties and functions of Ideas. They are:

1. Unchangeable, that is, always the same.

2. Eternal.

3. Uniform.

4. Intelligible but not perceptible and not mental, that is, independent of individual mentality.

5. Indissoluble.

6. Causes of being.

7. Incorporeal.

8. Non-temporal.

9. Non-spatial.

10.Existing without becoming.

11.Divine.

Now let us examine whether abstract structures have these properties.

1. Abstract structures are unchangeable, that is, always the same, because any change (transformation) of a structure is simply another structure. 
For instance, in mathematics, such structures as functions and operators represent transformations.

2. Abstract structures are eternal because they are unchangeable.

3. Abstract structures are uniform as they consist only of two types of constituents - elements and relations.

4. Abstract structures are intelligible but not perceptible and not mental, that is, independent of individual mentality, because they are not in mentality of people and cannot be reached by senses.

5. Abstract structures are indissoluble because they are unchangeable.

6. Abstract structures are reflected in embodied structures, which make things what they are, and in this way, structures are causes of being for all things.

7. Abstract structures are incorporeal because they do not belong to the physical world.

8. Abstract structures are non-temporal because they are unchangeable.

9. Abstract structures are non-spatial because they do not exist in the physical space.

10.Abstract structures do not become, they simply are because they are unchangeable.

Thus, we see that abstract structures have almost all properties of Ideas/Forms that Plato ascribes to them. We do not discuss here Plato's conjecture about divinity of structures as we do not have enough information to make a judgment on this issue.

\section{Why Structures Are Real}

According to contemporary science, an object is real if it is possible to test its existence by observation and experiment. This is how people substantiate reality of trees, mountains and tables. This is how physicists assert reality of atoms, electromagnetic waves and radiation. This is how astronomers verify reality of planets and stars.

To demonstrate reality of structures, let us consider the simplest structure called a fundamental triad (or a named set) and describe observations that confirm existence of this structure. Here we describe only ordinary fundamental triads (named sets) as the most simple structures.

In the symbolic representation, a fundamental triad (named set) has the form $\mathbf{X}=(X, f, I)$ in which $X$ is called the support of $\mathbf{X}, I$ is the component of names (reflector) of $\mathbf{X}$, and $f$ is the naming correspondence (reflection) of $\mathbf{X}$.

In the graphic representation, the following diagrams describe a fundamental triad: 


\section{Entity 1}

connection

or

\section{Essence 1}

\section{correspondence}

Entity 2

Thus, people can see structures but as Plato wrote about Ideas (eidos), they can comprehend structures only using their intelligence and knowledge.

Now let us describe how we can see a fundamental triad. Imagine, it is raining and you can see a cloud, the ground and streams of water, which go from the cloud to the ground. In essence, it is a fundamental triad $(X, f, I)$, in which the support $X$ is the cloud, the reflector $I$ is the ground and the streams of water form the reflection $f$.

Some will object that they do not see a fundamental triad. They will argue that they can see only a cloud, rain and ground. To understand why it happens, let us look into the history of human civilization.

For a long time, the majority of people have assumed that only those things (objects) were real that were comprehensible by the senses people had. However, even a material thing such as a table, tree or mountain, is comprehended not only by senses alone - understanding is necessary. For instance, if a person who lived in ancient Greece would see a plane, this person would not understand what he saw without explanation, and for many even a good explanation would not be enough.

To clearly see the reality of structures, it is useful to know that in some areas structures have played an indispensable role for a long time. For instance, in chemistry, researchers have recognized the significance of chemical structures almost from the very beginning of chemistry as a science. May be the most evident example of the importance of structures is the striking difference between diamond and graphite. Both materials (substances) are built entirely from the chemical element carbon and the difference in their properties is completely caused by their distinct crystal structures.

One more transparent example of a structure is an organization because organization is not so much people that work in the organization or material things used by these people but a definite structure. Without the organizational structure, it will be only a bunch of people and things. The same people can form different organizations depending on different organizational structures.

Embedded structures exist in diverse physical and mental things. At the same time, to figure out where the world of abstract structures exists, it is necessary to understand that there are different types of existence and physical or material existence is only one of them. This understanding 
demands a mental effort similar to the effort in seeing that many stars, which people can see only as points, are actually as big as the Sun and some are even bigger.

Note that when we observe structures, e.g., a fundamental triad, they are embedded structures.

Taking natural numbers as examples of structures, it is possible to ask where number 3 exists. Note that the number 3 is not the symbol " 3 " used as its name because number 3 has many other names: III in the Roman numerical system, 11 in the binary numerical system, three in English and so on. There are also different models of this number: an axiomatic model in formal arithmetic, for example, in Peano arithmetic, ${ }^{26}$ a set theoretical model as the class of all objects with the cardinality three ${ }^{27}$ or an abstract property as its model. ${ }^{28}$ However, having all names and models, it is natural to assume that all of them are names and models of some essence and this essence is an abstract structure called number 3 .

We see that this and other abstract structures exist in the constituent of the world of structures that contains abstract structures and we are able to find this structure by intelligent reasoning presented above. Moreover, it is possible to regard number 3 as several structures. For instance, in the context of a formal arithmetic, number 3 is an outer structure, while according to the set theoretical model, it is an inner structure.

\section{Resolution of the Aristotle-Plato Controversy}

Aristotle (384-322 B.C.E.) was a disciple of Plato but he did not accept Plato's theory of Ideas or Forms. Instead, he suggested his own approach to these issues.

Aristotle taught that each thing (physical object) is a synholon, which is a composition of substance (hyle) and form or idea (eidos). ${ }^{29}$ Form/idea comes into substance, but neither of them can exist independently in the physical world. Any form/idea is based on a prote hyle (a "first matter"), which is the hypokeimenon (foundation) of the form. Forms, according to Aristotle,

26. Joseph Shoenfield, Mathematical Logic (Reading, Massachusetts: Addison-Wesley, 2001).

27. Abraham Fraenkel, \& Yehoshua Bar-Hillel, Foundations of Set Theory (Amsterdam: North Holland P.C., 1958).

28. Mark Burgin, Numbers as properties, Abstracts of papers presented to the American Mathematical Society 10, no. 1 (1989).

29. Aristotle, The Complete Works of Aristotle (Princeton: Princeton University Press, 1984). 
determine essence of things. A philosophical teaching about relations between form and substance is called hylomorphism. ${ }^{30}$

Note that the Greek word form is usually interpreted as the sight or appearance of a thing, while Aristotle treated forms in a more general way.

Aristotle defines substance of a thing as "that out of which" this thing is made or as the "constituents" of this thing. As a result, substance is not necessarily physical. For instance, letters are the substance of words. Aristotle even calls the parts of a geometrical shape by the name intelligible substance.

Substance is only potentiality of things as they do not exist without form, which is actuality of things. According to Aristotle's theory of perception, the senses perceive an object by receiving its form. For instance, bronze is the matter of both a bronze statue and a bronze sphere. They have the same substance but different forms. When a bronze statue is transformed into a bronze sphere, the bronze as the substance remains constant throughout the change. While bronze is a bronze sphere's substance, roundness is its form. Bronze is potentially a bronze sphere. It becomes actually a bronze sphere when it acquires roundness, which is an actuality of the bronze sphere. However, forms need not always be shapes - shape is only a kind of forms.

We have demonstrated that it is possible to rigorously interpret Platonic Forms/Ideas as structures. The same is true for Aristotle's forms. They can be also interpreted as structures. It is interesting that implicitly physicists already did it although the explicit statement that Aristotle's forms are structures was only in Burgin. ${ }^{31}$ To show this, let us look at what scientists have written about structures.

The outstanding physicist Arthur Stanley Eddington (1882-1944) wrote that physical reality has substance and structure. ${ }^{32}$ This statement shows that structures are prevalent in the physical world - any physical system has its structure.

In a similar way, another outstanding physicist Erwin Schrödinger (18871961) asserted that structure was the basic feature of an object. He wrote:

"... in palpable bodies, composed of many atoms, individuality arises out of the structure of their composition, out or shape or form, or organization, as we might call it in other cases. The identity of the material, if there is any, plays a subordinate role. You may see this particularly well in cases when you speak of "sameness" though the material has definitively changed."33

30. Joseph Wulftange, \& Merrill Greene, Hylomorphism and contemporary physics (Woodstock, MD: Woodstock College Press, 1952).

31. Burgin, Theory of Named Sets, \& Structural Reality.

32. Arthur Eddington, The Theory of Relativity and its Influence on Scientific Thought (Oxford: Clarendon Press, 1922).

33. Erwin Schrödinger, Science and humanism (New York: Cambridge University Press, 1952). 
As we know substance is only a general term (name), which has no comprehensive definition because any attempt to further this naming immediately involves attachment of some structure. At the same time, as we have seen, it is possible to develop with high precision the general concept of structure.

Another great physicist Paul Adrien Maurice Dirac (1902-1984) asserted that with the advance of quantum physics, physical objects start becoming more structures than real things. ${ }^{34}$ The contemporary physicist Max Tegmark advocates an even more extreme approach to physics suggesting the Mathematical Universe Hypothesis, in which he assumes the external physical reality to be a mathematical structure. ${ }^{35}$ He believes that this unification of physics and mathematics would allow physicists to understand reality more deeply than most dreamed possible.

All these examples show that if we interpret Forms/Ideas as structures, we can see that physicists write exactly the same as Aristotle did millennia ago. The only difference is that structure is an exact mathematical and thus, scientific concept, while Aristotle's form is a vague philosophical notion. Nevertheless, we can admire the genius of Aristotle, who was able to describe the structural organization of the physical world with high accuracy.

Now to reconcile approaches of Plato and Aristotle to Ideas or Forms, we use the general theory of structures, which tells us that there are two sorts of structures: abstract structures and embodied structures. ${ }^{36}$ An embodied structure is a structure of some system, while an abstract structure is a structure by itself. This allows us to associate embodied structures with Aristotle's forms and abstract structures with Plato's Ideas.

Regarding abstract structures as a scientific representation of Plato's Ideas, we can see that they exist in reality but this is a different kind of reality. As Burgin ${ }^{37}$ explains, there are various types and kinds of reality and structural reality is one of the three basic types of reality that constitute our world. Namely, there are physical reality, mental reality and structural reality.

The world of structures is a new type of reality and it demands a lot of intelligence, as Plato already forecasted, to understand this. Although in our times, it might be easier to do this because the development of quantum physics also discovered a new kind of reality - quantum reality, which is essentially different from the reality of the everyday life. As Bohr declared during a conversation with Åage Petersen: "There is no quantum world. There

34. Paul Dirac, The origin of quantum field theory, The Birth of Particle Physics (Cambridge: Cambridge University Press, 1983).

35. Max Tegmark, The Mathematical Universe.

36. Burgin, Structural Reality.

37. Ibid. 
is only an abstract quantum description."38 It means that quantum theory is not a theory of objects in a micro-world but a structural description of quantum reality.

Even before the discovery of the world of structures, people developed a science that studies this world and this science is called mathematics. ${ }^{39}$ It is interesting to know that similar to other sciences, mathematics has theoretical, experimental and applied parts. ${ }^{40}$

In addition, the general theory of structures offers a better understanding of other ontological and epistemological conceptions of Plato. In particular, to better explain his theory of Ideas, Plato brings in the metaphor of the Divided Line $(\gamma \varrho \alpha \mu \mu \eta \dot{~ \delta i ́ ~} \alpha \tau \varepsilon \tau \mu \eta \mu \varepsilon ́ v \eta$ in Greek), when Socrates explains it to Glaucon in the Republic. Socrates suggests dividing a segment of a straight line into four segments (Figure 2) and explains that they represent four separate "affections" $(\pi \alpha \theta \eta \dot{\eta} \mu \alpha \tau \alpha)$ of the psyche. These affections are introduced in succession as corresponding to the escalating levels of reality and truth from

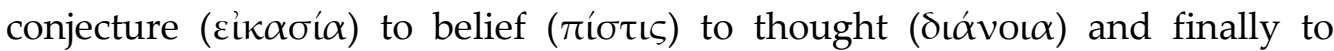
understanding (vónoıs).

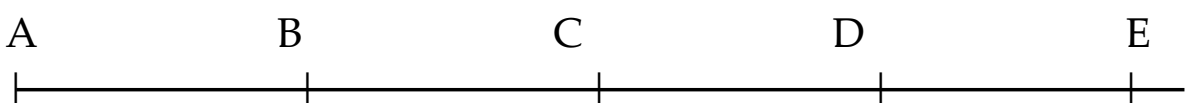

Figure 2. The Divided Line

The left half $\mathrm{AC}$ of the segment $\mathrm{AE}$ corresponds to the visible world, while the right half $\mathrm{CE}$ of the segment $\mathrm{AE}$ is associated with the intelligible world. In this schema, the segment $A B$ represents reflections of physical things and the segment $\mathrm{BC}$ the physical things themselves.

Plato describes the segment $\mathrm{CD}$ as the "lower" part of the intelligible world containing abstract mathematical objects such as geometric lines and

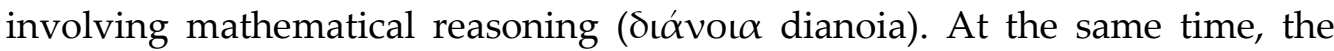
segment DE corresponds to the "higher" part of the intelligible world containing principles, paradigms and general patterns.

The structural interpretation of Ideas provides a scientific explanation and interpretation of the Divided Line metaphor.

- The segment $A B$ represents mental images of physical things.

- The segment BC represents physical (sensible) things themselves.

38. Åage Petersen, The philosophy of Niels Bohr, Bulletin of the Atomic Scientists 19, no. 7 (1963).

39. Mark Burgin, Is it Possible that Mathematics gives new Knowledge about Reality? Philosophical and Sociological Thought, no. 1, (1994).

40. Mark Burgin, On the Nature and Essence of Mathematics (Kiev: Ukrainian Academy of Information Sciences, 1998) (In Russian). 
- The segment CD represents embodied individual structures of physical things.

- The segment DE represents abstract pattern structures.

In this interpretation, we discern two types of structures (Ideas): pattern structures and individual structures.

Definition 7: A pattern structure is a structure common to several (often, to many) systems. For instance, the structure of a triangle is a pattern structure because it is the same for a multitude of triangles.

In the Republic, Plato writes, "there is one Idea for each set of many things to which we give the same name." This exactly relates to a pattern structure, which is the "one over the many."

It is possible to show that a structure in the sense of Bourbaki, ${ }^{41}$ is a special kind of abstract pattern structures because axioms are kinds of relations at a higher level defined by formulas. However, not all structures in the sense of Definition 5 can be represented by structures in Bourbaki's sense. For instance, it is impossible to represent even structures where a system is considered as part of itself. Indeed, according to the axioms of set theory, a set cannot be an element of itself, while Bourbaki's definition of structure is based on sets. ${ }^{42}$

Definition 8: An individual structure is a structure of some individual object. For instance, taking a definite triangle and determining its structure so that it would define a unique triangle, we obtain an individual structure of this triangle.

In their definition, Bourbaki deal only with pattern structures ignoring individual structures because they assume that mathematics studies patterns. However, in principle, mathematics also studies individual structures.

\section{Conclusion}

We described the main precepts of Plato's theory of Ideas and analyzed the concept of a structure demonstrating how it is possible to treat structures as the scientific interpretation of Platonic Ideas. At the same time, the development of technology extends the scope of our analysis posing new problems and bringing in new challenges for philosophers and other thinkers.

In his theory, Plato assumed that the physical world was the sensible realm, as people could grasp it with their five senses, while the world of Ideas was the intelligible realm, as people could comprehend it only with their intellect. However, the development of technology changed the situation.

41. Nicolas Bourbaki, Theorie des Ensembles.

42. Ibid. 
Now people use many technical devices to get the picture of physical objects, i.e., to comprehend them, - they use a variety of telescopes, microscopes, binoculars, tomographic systems, detectors and many others. As a result, on the one hand, sensing becomes mediated by technical devices, while on the other hand, comprehension of observed objects demands intelligence when many of these devices are utilized. Often computations are necessary to make sense of the data produced by such devices.

At the same time, computers started to extend human intelligence. Consequently, it becomes possible to know structures with the help of computers although computers employ intelligence, which embedded in to them by people. Computers discover structures of chemical elements in chemistry and biological structures in genetics and its computerized part biological informatics.

Besides, computers can prove theorems developing mathematical structures, write programs developing computational structures and construct new chemical and biological structures. In such a way, computers cognize not only embedded structures but also abstract structures, or Ideas in the sense of Plato.

Thus, technology extends ways of comprehension of all kinds and types of reality with its basic forms - physical, mental and structural reality.

\section{Acknowledgements}

I am grateful to reviewers for their helpful comments.

\section{Bibliography}

Aristotle. The Complete Works of Aristotle. Princeton: Princeton University Press, 1984.

Bourbaki, Nicolas. Theorie des Ensembles (Theory of Sets). Paris: Hermann, 1960.

Bourbaki, Nicolas. Structures. Paris: Hermann, 1957.

Bourbaki, Nicolas. L'architecture des mathématiques, Legrands courants de la pensée mathématiques (The architecture of mathematics, Great currents of mathematical thinking). Les Cahiers du Sud (1948): 35-47.

Burgin, Mark. Structural Reality. New York: Nova Science Publishers, 2012.

Burgin, Mark. Theory of Named Sets. New York: Nova Science Publishers, 2011.

Burgin, Mark. Theory of Information: Fundamentality, Diversity and Unification, World Scientific. New York, London, Singapore, 2010.

Burgin, Mark. Structures in mathematics and beyond, Proceedings of the $8^{\text {th }}$ Annual International Conference on Statistics, Mathematics and Related Fields. Honolulu, Hawaii, 2009. 
Burgin, Mark. On the Nature and Essence of Mathematics. Kiev: Ukrainian Academy of Information Sciences, 1998 (In Russian).

Burgin, Mark. Fundamental Structures of Knowledge and Information. Kiev: Ukrainian Academy of Information Sciences, 1997 (In Russian).

Burgin, Mark. Is it Possible that Mathematics gives new Knowledge about Reality? Philosophical and Sociological Thought no. 1 (1994): 240-249.

Burgin, Mark, \& Kuznetsov, Vladimir. Introduction to Modern Exact Methodology of Science. Moscow: International Science Foundation, 1994 (In Russian).

Burgin, Mark. Is it Possible that Mathematics gives new Knowledge about Reality? Philosophical and Sociological Thought no. 1 (1994): 240-249 (In Russian and Ukrainian).

Burgin, Mark. What is the Surrounding World Built of (The Ontological Aspect). Philosophical and Sociological Thought no. 8 (1991): 54-67 (In Russian).

Burgin, Mark. Numbers as properties, Abstracts of papers presented to the American Mathematical Society 10, no. 1 (1989).

Capuro, Rafael, \& Hjorland, Birger. The Concept of Information. Annual Review of Information Science and Technology 37, no. 8 (2003): 343-411.

Corry, Leo. Modern Algebra and the Rise Mathematical Structures. Basel, Boston, Berlin: Birkhäuser, 1996.

Dirac, Paul. The origin of quantum field theory. The Birth of Particle Physics. Cambridge: Cambridge University Press, 1983.

Eddington, Arthur. The Theory of Relativity and its Influence on Scientific Thought. Oxford: Clarendon Press, 1922.

Fraenkel, Abraham, \& Bar-Hillel, Yehoshua. Foundations of Set Theory. Amsterdam: North Holland P.C., 1958.

Gerson, Lloyd. Plotinus. The Stanford Encyclopedia of Philosophy, 2014.

Grossmann, Reinhardt. The Fourth Way: A Theory of Knowledge. Bloomington, Indianapolis: Indiana University Press, 1990.

Leśniewski, Stanisław. Podstawy ogólnej teoryi mnogosci I, Prace Polskiego Kola Naukowego $w$ Moskwie, Sekcya matematyczno-przyrodnicza, 1916 (trans. Foundations of the General Theory of Manifolds I, Stanisław Leśniewski, Collected Works. Dordrecht: Kluwer 1 (1992): 129-173).

Malcev, Anatolij. Algebraic systems. Springer, 1973.

Petersen, Åage. The philosophy of Niels Bohr. Bulletin of the Atomic Scientists 19, no. 7 (1963): 8-14.

Popper, Karl. Objective knowledge: An evolutionary approach. New York: Oxford University Press, 1979.

Popper, Karl. Replies to my critics. The Philosophy of Karl Popper. Open Court, La Salle, IL, 1974.

Plato. The Collected Dialogues of Plato. Princeton University Press, Princeton, 1961.

Robinson, Abraham. Introduction to Model Theory and Metamathematics of Algebra. Amsterdam, New York: North-Holland, 1963.

Schrödinger, Erwin. Science and humanism. New York: Cambridge University Press, 1952.

Skagestad, Peter. Thinking with machines: Intelligence augmentation, evolutionary epistemology, and semiotics. Journal of Social and Evolutionary Systems 16 (1993): 157-180.

Simons, Peter. Parts: A Study in Ontology. Oxford: Oxford University Press, 1987. 
Shoenfield, Joseph. Mathematical Logic. Reading, Massachusetts: Addison-Wesley, 2001.

Tegmark, Max. The Mathematical Universe. Foundations of Physics 38, no. 2 (2008): 101150.

Wulftange, Joseph, \& Greene, Merrill. Hylomorphism and contemporary physics. Woodstock, MD: Woodstock College Press, 1952.

Yaglom, Isaac. Mathematical Structures and Mathematical Modeling. Moscow: Sov. Radio, 1980 (In Russian). 